\title{
Marktmacht und Verdrängungsmissbrauch
}

Eine rechtsvergleichende Neubestimmung des Verhältnisses von Recht und Ökonomik in der Missbrauchsaufsicht über marktbeherrschende Unternehmen

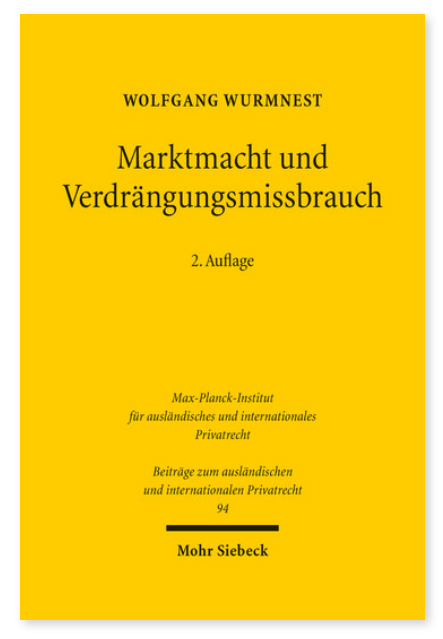

2., überarbeitete Auflage; 2012. XXX, 694 Seiten. BtrIPR 94

ISBN 978-3-16-152298-7

DOI 10.1628/978-3-16-152298-7

eBook PDF $119,00 €$

ISBN 978-3-16-151914-7

Leinen $119,00 €$
Vor dem Hintergrund der in ganz Europa geführten Debatte um den »more economic approach« im Kartellrecht stellt Wolfgang Wurmest die Missbrauchsaufsicht über marktbeherrschende Unternehmen auf den Prüfstand. Auf Grundlage einer rechtsökonomischen Analyse und eines Vergleichs mit dem US-amerikanischen Recht zeigt er auf, wie das deutsche und das europäische Missbrauchsverbot auszulegen und anzuwenden sind, so dass unter Berücksichtigung der Eigengesetzlichkeiten des Rechts modernen ökonomischen Erkenntnissen Rechnung getragen wird. Die zweite Auflage bringt das Werk auf den Stand von April 2012 und berücksichtigt bereits den Regierungsentwurf für die 8. GWB-Novelle, mit der eine Neuordnung der deutschen Missbrauchskontrolle angestrebt wird.

»Pflichtlektüre für alle Kartellrechtler« Volker Emmerich Die Aktiengesellschaft 2011,724 »Die große Stärke der Arbeit liegt [...] darin, die grundlegenden Ausführungen schlüssig mit der Analyse von spezifischen Anwendungsproblemen der Missbrauchsaufsicht zu verbinden. [...] Insgesamt kann die vorliegende Arbeit daher als sehr gelungen gelten. «Arndt Christiansen Wirtschaft und Wettbewerb 2011, 621-622

Wolfgang Wurmnest ist Inhaber des Lehrstuhls für Bürgerliches Recht, Wirtschaftsrecht, Internationales Privat- und Zivilverfahrensrecht sowie Rechtsvergleichung an der Juristischen Fakultät der Universität Augsburg.

Jetzt bestellen:

https://mohrsiebeck.com/buch/marktmacht-und-verdraengungsmissbrauch-9783161522987?no_cache=1 order@mohrsiebeck.com

Telefon: +49 (0)7071-923-17

Telefax: +49 (0)7071-51104 